\title{
Intussusception after Colonoscopy: A Case Report and Review of Literature
}

\author{
Wan Amir Wan Hassan and William Teoh \\ Colorectal Surgery, Department of Surgery, School of Clinical Sciences at Monash Health, Monash University, Melbourne, Victoria, Australia
}

Intussusception after colonoscopy is an unusual complication. A MEDLINE search revealed only 7 reported cases. We present a report of a 28-year-old man who developed abdominal pain several hours after routine colonoscopy and in whom computed tomography (CT) revealed colocolic intussusception. We postulate that this condition is iatrogenic and induced by suctioning of gas on withdrawal of the colonoscope. A common observation among the reported cases was abdominal pain several hours after colonoscopy and rightsided intussusception. All cases had colonoscopy reaching the right side of the colon. Treatment for adult intussusception remains controversial with regard to reduction versus resection, especially given the high association with a pathological cause and malignancy. Among the 8 reported cases, only the current case did not require surgery. A combination of benign colonoscopy, CT, and the clinical picture should provide sufficient information to initially choose a more conservative treatment approach.

Clin Endosc 2018;51:591-595

Key Words: Colonoscopy; Intussusception; Colon; Iatrogenic disease; Adult

\section{INTRODUCTION}

Intussusception after colonoscopy is rare. A MEDLINE search revealed only 7 reported cases. We present a report of a 28 -year-old man who developed abdominal pain several hours after routine colonoscopy and in whom computed tomography (CT) revealed colocolic intussusception.

\section{CASE REPORT}

A 28-year-old man presented with a 2-day history of crampy right iliac fossa pain that began a few hours after

Received: March 12, 2018 Accepted: May 21, 2018

Correspondence: Wan Amir Wan Hassan

Colorectal Surgery, Department of Surgery, School of Clinical Sciences at Monash Health, Monash University, Dandenong Hospital, Monash Health, 135 David Street, Melbourne, Victoria 3175, Australia

Tel: +61-9554-8657, Fax: +61-9554-1177, E-mail: wanamir@gmail.com ORCID: https://orcid.org/0000-0002-6022-3690

(c) This is an Open Access article distributed under the terms of the Creative Commons Attribution Non-Commercial License (http://creativecommons.org/ licenses/by-nc/3.0) which permits unrestricted non-commercial use, distribution, and reproduction in any medium, provided the original work is properly cited. gastroscopy and colonoscopy. The pain was associated with nausea, vomiting, and diarrhea, with a small amount of blood mixed in the stool.

The endoscopy procedure was performed at an external site to investigate iron deficiency anemia. Gastroscopy revealed erosive antral gastritis and duodenal mucosa that appeared atrophic. Colonoscopy was normal to the distal terminal ileum. Biopsies were taken from the stomach, duodenum, terminal ileum, and colon. Histology revealed patchy, mildly active chronic gastritis, which was negative for Helicobacter pylori. Other biopsies were normal.

Past medical history included iron deficiency anemia and vitamin $\mathrm{D}$ deficiency.

On examination, he had tachycardia at 104 beats/min and fever of $37.7^{\circ} \mathrm{C}$. He had right abdominal tenderness with localized guarding.

Laboratory findings showed leukocytosis of $13.2 \times 10^{9} / \mathrm{L}$ (normal range, $4.0-11.0 \times 10^{9} / \mathrm{L}$ ) and C-reactive protein level of $252 \mathrm{mg} / \mathrm{L}$ (normal range, $0-5 \mathrm{mg} / \mathrm{L}$ ).

Abdominal CT revealed a 7-cm-long ascending colon to the hepatic flexure colocolic intussusception associated with congestive edema of the proximal large bowel (Fig. 1). There was no evidence of perforation or small bowel obstruction. No ob- 
vious mass lesion acting as an intussusceptum was appreciable on CT.

He was managed with fasting, nasogastric tube decompression, maintenance intravenous fluids, and intravenous ceftriaxone and metronidazole. The symptoms improved without immediate surgery. Thus, colonoscopy was performed with intention to proceed to laparotomy if required. The right colon appeared inflamed and edematous, with a large submucosal nodular swelling at the proximal extent of the inflammation in the proximal transverse colon (Figs. 2, 3). The terminal ileum was entered and appeared normal. Biopsies were taken from the inflamed colon and the suspected intussusceptum site. As intussusception was not present during colonoscopy and the patient was clinically better, laparotomy was deemed unnecessary. Histology showed acute colitis with features not typical of infective or inflammatory colitis but consistent with

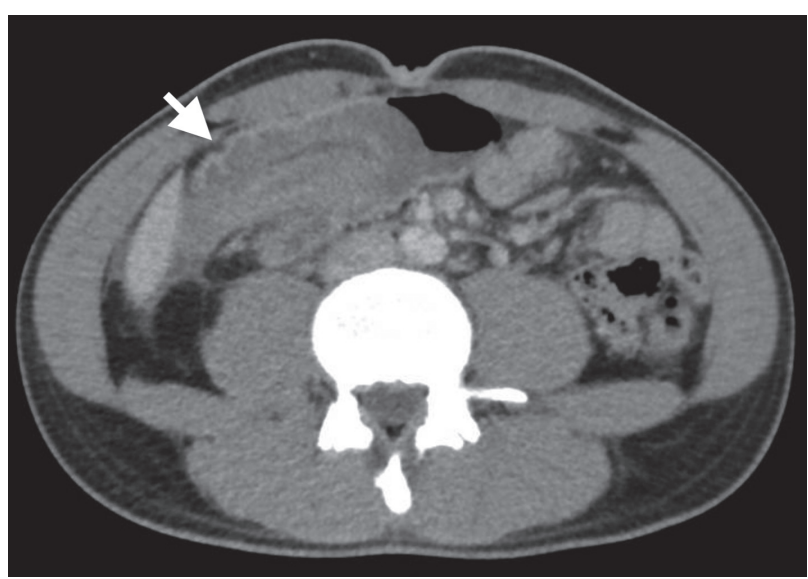

Fig. 1. Computed tomography demonstrating a right-sided colocolic intussusception.

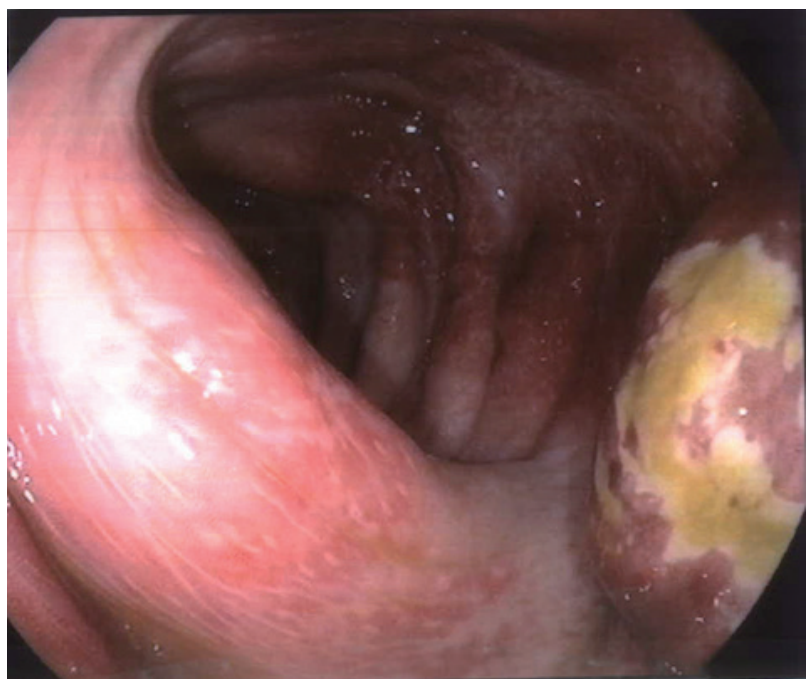

Fig. 2. Colonoscopy_inflamed and edematous colonic mucosa with a large submucosal nodular swelling. the effect of recent intussusception.

The patient continued to improve with normalizing inflammatory markers, and was discharged home 2 days later.

\section{DISCUSSION}

Intussusception is an invagination of the bowel, in which a proximal segment (the intussusceptum) telescopes into the lumen of the adjacent distal segment (the intussuscipiens).

The occurrence of intussusception is rare in adults, representing approximately $5 \%$ of all intussusception cases. ${ }^{1}$ In adults, $70 \%-90 \%$ of intussusception is associated with a pathological cause that acts as the lead point in the mechanism of intussusception, such as adhesions, inflammatory lesions, benign tumors, malignant lesions, and Meckel's diverticulum. ${ }^{1-3}$ Malignant causes have been attributed for $24 \%$ of adult enteroenteric intussusception. In contrast, there is a far higher association of adult colonic intussusception with malignancy, at approximately $54 \%-68 \% .^{1,2}$ Idiopathic intussusception, the mechanism of which is still poorly understood, accounts for approximately $8 \%-30 \%$ of all intussusception and is more common in small bowel intussusception. ${ }^{3-5}$

Intussusception after colonoscopy, however, is extremely uncommon. The literature review revealed that only 8 cases, including the present case, have been reported to date. The first case was reported in 2000 by Yamazaki et al.; other cases are mentioned in Table $1{ }^{6-12}$ The age of presentation ranged from 19 to 73 years, with a male predominance of 5:2. All patients had onset of abdominal pain within hours of colonoscopy and presented early to the hospital. Remarkably, all

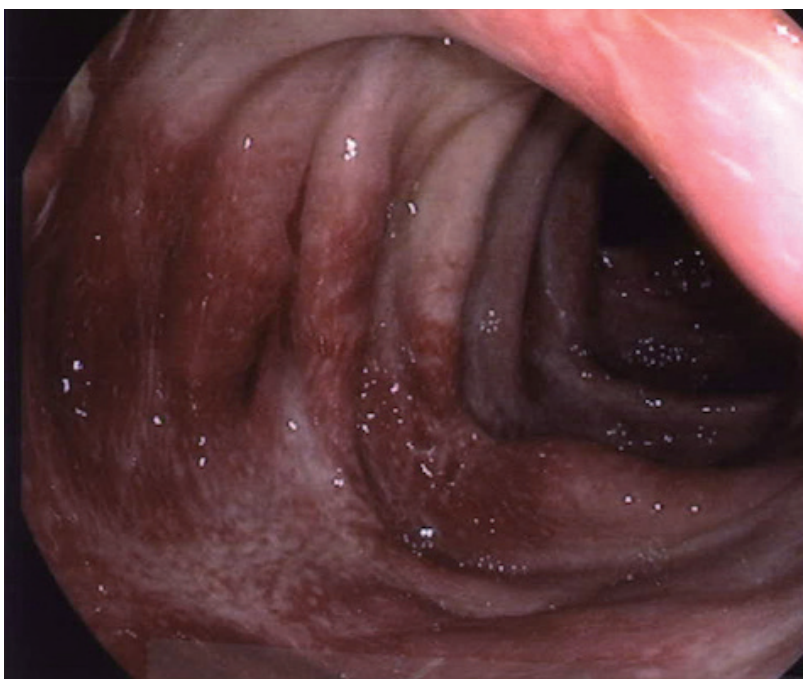

Fig. 3. Colonoscopy_inflamed and edematous colonic mucosa. 
sites of intussusception after colonoscopy were on the right side of the colon. Only 1 case was an ileocolic intussusception, while the rest were colocolic intussusceptions. All patients had undergone colonoscopy reaching the right colon. Three cases achieved terminal ileum intubation but terminal ileum biopsy was only reported in 1 case. Of those 3 cases, 1 had an unresectable large polyp in the terminal ileum.

Four cases were managed with laparotomy, 3 of which proceeded with right hemicolectomy, and 1 had an ileocolic resection. The other 3 cases were managed with laparoscopy. Of those, 2 had laparoscopic reduction, and 1 proceeded with colonoscopy to confirm the viability of the colonic mucosa. One laparoscopic case concluded with an endoscopic ileocolic resection. Only our case did not require operative management. Only 1 case had a potential cause for intussusception: a large pedunculated polyp in the terminal ileum. None of the cases had malignant pathology.

A mechanism of intussusception after colonoscopy has been postulated by several authors. Yamazaki et al. suggested that intussusception was induced by hyperperistalsis, which would vent gas and empty the insufflated colon after colonoscopy. ${ }^{6}$
Ho et al. added that post polypectomy edema could be acting as the lead point; however, 2 of the cases (Theodoropoulou et al. and Lasithiotakis et al.) did not allude to any biopsy being performed. In the sole case of ileocolic intussusception, the ileal polyp was the potential lead point. ${ }^{78,10}$ Lasithiotakis et al. speculated that aspiration of insufflated air while withdrawing the colonoscope, coupled with ongoing propulsive small intestinal peristalsis and relaxation of the ileocecal valve, led to invagination of the ileal polyp through the ileocecal valve, and development of ileocolic intussusception. ${ }^{10}$

We hypothesize that aspiration of gas during withdrawal of the colonoscope would have created a vacuum effect to draw in the proximal colon, causing it to collapse and invaginate into the distal colon as the colonoscope was retrieved. We postulate that this is a phenomenon seen in the right colon because the cecum is mobile and free to move within the abdomen. A similar phenomenon was observed in vivo in a case reported by Santos-Antunes et al., in which colonoscopy was performed for a patient with a colonic volvulus. ${ }^{13}$ The authors observed intussusception occurring during colon decompression and retrieval of the scope. ${ }^{13}$

Table 1. Review of Reported Post Colonoscopic Intussusception Cases

\begin{tabular}{|c|c|c|c|c|c|c|}
\hline Study & $\begin{array}{l}\text { Age/ } \\
\text { Gender }\end{array}$ & $\begin{array}{l}\text { Pre-morbid colonoscopy } \\
\text { report }\end{array}$ & $\begin{array}{l}\text { Presenting } \\
\text { complaints }^{\text {a) }}\end{array}$ & $\begin{array}{l}\text { Site of intus- } \\
\text { susception }\end{array}$ & $\begin{array}{l}\text { Type of intus- } \\
\text { susception }\end{array}$ & Operative strategy \\
\hline $\begin{array}{l}\text { Yamazaki et al. } \\
(2000)^{6}\end{array}$ & $48 / \mathrm{M}$ & $\begin{array}{l}\text { Two } 5 \mathrm{~mm} \text { polyp in the caecum } \\
\text { and hepatic flexure, biopsied }\end{array}$ & $\begin{array}{l}\text { 1/7 abdom- } \\
\text { inal pain }\end{array}$ & Right colon & Colo-colic & $\begin{array}{l}\text { Laparotomy+Ileocolic } \\
\text { resection }\end{array}$ \\
\hline $\begin{array}{l}\text { Theodoropoulou } \\
\text { et al. }(2009)^{7}\end{array}$ & $19 / \mathrm{M}$ & Ileo-colonoscopy & $\begin{array}{l}\text { 1/7 abdom- } \\
\text { inal pain }\end{array}$ & Right colon & $\mathrm{N} / \mathrm{A}$ & $\begin{array}{l}\text { Laparotomy+Right hemi- } \\
\text { colectomy }\end{array}$ \\
\hline Ho et al. $(2010)^{8}$ & $32 / \mathrm{M}$ & $\begin{array}{l}\text { Small polyp mid ascending } \\
\text { colon removed with snare } \\
\text { cautery }\end{array}$ & $\begin{array}{c}1 / 7 \text { RLQ } \\
\text { pain V }\end{array}$ & $\begin{array}{l}\text { Ascending } \\
\text { colon }\end{array}$ & Colo-colic & $\begin{array}{c}\text { Laparoscopic reduction } \\
\text { +intraoperative colonosco- } \\
\text { py }\end{array}$ \\
\hline $\begin{array}{l}\text { Nachnani et al. } \\
(2012)^{9}\end{array}$ & $73 / \mathrm{F}$ & $\begin{array}{l}\text { Normal to caecum+random } \\
\text { colonic biopsy }\end{array}$ & $\begin{array}{l}\text { 1/7 RLQ } \\
\text { pain }\end{array}$ & $\begin{array}{l}\text { Hepatic flex- } \\
\text { ure }\end{array}$ & Colo-colic & Laparoscopic reduction \\
\hline $\begin{array}{l}\text { Lasithiotakis et al. } \\
\qquad(2012)^{10}\end{array}$ & $\begin{array}{c}58 / \\
M ? F^{b)}\end{array}$ & $\begin{array}{l}\text { 4-cm diameter pedunculated } \\
\text { polyp in the terminal ileum } \\
\text { approximately } 10 \mathrm{~cm} \text { from the } \\
\text { ileocecal valve }\end{array}$ & $\begin{array}{l}\text { 1/7 abdom- } \\
\text { inal pain } \\
\text { NVD }\end{array}$ & $\begin{array}{c}\text { Terminal } \\
\text { ileum }\end{array}$ & Ileocolic & $\begin{array}{l}\text { Laparotomy+Right hemi- } \\
\text { colectomy }\end{array}$ \\
\hline Lee et al. $(2013)^{11}$ & $47 / \mathrm{M}$ & $\begin{array}{l}\text { 15-mm non-polypoid lesion } \\
\text { (0-IIa type) located at the } \\
\text { caecal base, polypectomy }\end{array}$ & $\begin{array}{l}\text { 1/7 abdom- } \\
\text { inal pain }\end{array}$ & Caecum & Colo-colic & $\begin{array}{l}\text { Colonoscopy+laparotomy } \\
\text { +Right hemicolectomy }\end{array}$ \\
\hline Min et al. $(2017)^{12}$ & $31 / \mathrm{F}$ & $\begin{array}{l}\text { No significant abnormality, } \\
\text { mild congestion throughout } \\
\text { the colon. Patent colorectal } \\
\text { anastomosis in mid rectum }\end{array}$ & $\begin{array}{l}\text { 1/7 abdom- } \\
\text { inal pain }\end{array}$ & Right colon & Colo-colic & $\begin{array}{l}\text { Laparoscopic exploration } \\
+ \text { ileocolic resection }\end{array}$ \\
\hline Current (2017) & $28 / \mathrm{M}$ & $\begin{array}{l}\text { Normal to ileum. Random } \\
\text { colon biopsies }\end{array}$ & $\begin{array}{l}\text { 2/7 abdom- } \\
\text { inal pain } \\
\mathrm{NV} \text { fever }\end{array}$ & Right colon & Colo-colic & Colonoscopy \\
\hline
\end{tabular}

RLQ, right lower quadrant; NVD, nausea, vomiting, diarrhea; N/A, not available.

a) $1 / 7=1$ day, $2 / 7=2$ day, whereby the denominator 7 indicates 7 days in one week.

${ }^{b}$ It was initially written as 58 year old man in the abstract but changed to 58 year old women in the case report. 
Clinical presentation of adult intussusception can be nonspecific but generally involves abdominal pain and signs of bowel obstruction. ${ }^{14}$ Symptoms of intussusception after colonoscopy may be common to those of other complications after colonoscopy. Hence, CT was the preferred diagnostic tool for all reported cases of intussusception after colonoscopy.

The radiologic finding in CT is described as a "target sign", with the intussusceptum in the center and the edematous intussuscipiens forming the external ring. ${ }^{5}$ While some studies have shown that a lead point is identifiable in up to $32 \%$ of cases ( 28 of 88 scans reviewed) it may not always be distinguishable in prolonged intussusception. ${ }^{3}$ Impaired circulation of the mesenteric vessels may lead to bowel edema and thickened bowel loops make it difficult to discern a lead mass from inflammation because of the amorphous appearance. ${ }^{5,15}$ However, additional valuable information, such as metastasis or lymphadenopathy, is readily obtained with $\mathrm{CT}$ and may indicate an underlying pathology. ${ }^{16}$ Ultrasound tends to be less accurate for diagnosis in adults than in children but may still reveal a target or doughnut-ring sign. ${ }^{14}$

Treatment for adult intussusception remains controversial, mainly with regard to reduction versus primary resection. Because there is a high association with a pathological cause in adult intussusception and malignancy, especially in colonic cases, most authors agree on surgical exploration. Prior to the mid-1950s, manual reduction before resection was advocated. This would, in theory, permit a more limited resection. ${ }^{4}$ However, with the increased awareness of the association with malignancy, the concepts of seeding and venous dissemination upon operative manipulation have led to recommendations for primary resection without initial reduction as the treatment of choice, except in unusual circumstances. Nevertheless, there have been no significant data to support this concern. ${ }^{1,2,4,17}$ In recent years, the widespread use of CT has increased the detection of intussusception, particularly in individuals without a lead point. ${ }^{3,15}$ More recent studies have started to re-evaluate the operative mandate of managing adult intussusception. Rea et al. conducted a retrospective study of 170 adult intussusception cases. ${ }^{18}$ Excluding those that were terminally ill and explorative trauma cases, $84 \%$ were managed nonoperatively, including those that were symptomatic (63.6\%). Fifteen of the explored patients did not have intussusception on the table. However, it is important to note that $93 \%$ of this nonoperated study group were enteroenteric adult intussusceptions. ${ }^{18}$ In another study, asymptomatic patients without a lead point on CT were regarded safe to manage without an operation, assuming a transient phenomenon. Operative exploration in asymptomatic patients was also routinely negative. Similarly, the majority of patients had enteroenteric intussusception. ${ }^{3}$
As the current general consensus that surgical resection should be performed for colonic adult intussusception due to the high association with neoplastic etiology, excluding the single case with the large polyp, it is not surprising that 4 of the 7 reported cases were managed with bowel resection despite benign colonoscopy.

Considering that patients with an intussusception after colonoscopy would already have undergone a recent colonoscopy, such cases are unique compared to the usual demographic of adult intussusception that mandates operative management. The combination of normal premorbid colonoscopy, CT without signs of bowel compromise, and a clinically stable patient, there should be enough information for clinician to opt for a more conservative initial approach with a colonoscopy.

Conflicts of Interest

The authors have no financial conflicts of interest.

\section{Author contributions}

Conceptualization: William Teoh

Data curation: Wan Amir Wan Hassan

Formal analysis: WAWH

Funding acquisition: WAWH

Investigation: WAWH

Methodology: WAWH

Resources: WAWH

Supervision: WT

Validation: WAWH

Visualization: WAWH

Writing-original draft: WAWH

Writing-review \& editing: WAWH, WT

\section{REFERENCES}

1. Weilbaecher D, Bolin JA, Hearn D, Ogden W 2nd. Intussusception in adults. Review of 160 cases. Am J Surg 1971;121:531-535.

2. Sanders GB, Hagan WH, Kinnaird DW. Adult intussusception and carcinoma of the colon. Ann Surg 1958;147:796-804.

3. Onkendi EO, Grotz TE, Murray JA, Donohue JH. Adult intussusception in the last 25 years of modern imaging: is surgery still indicated? J Gastrointest Surg 2011;15:1699-1705.

4. Nagorney DM, Sarr MG, McIlrath DC. Surgical management of intussusception in the adult. Ann Surg 1981;193:230-236.

5. Azar T, Berger DL. Adult intussusception. Ann Surg 1997;226:134-138.

6. Yamazaki T, Okamoto H, Suda T, et al. Intussusception in an adult after colonoscopy. Gastrointest Endosc 2000;51:356-357.

7. Theodoropoulou A, Konstantinidis K, Kteniadakis S, et al. Intussusception following enteroscopy and ileo-colonoscopy in an adult with acquired immune deficiency syndrome. Endoscopy 2009;41 Suppl 2: E162-E163.

8. Ho MM, Park JJ, Prasad LM. Post colonoscopy colonic intussusception reduced via a laparoscopic approach. JSLS 2010;14:596-599.

9. Nachnani J, Burns E, Margolin D, Clarkston WK. Colocolonic intussusception after colonoscopy. Gastrointest Endosc 2012;75:223-225.

10. Lasithiotakis K, Grisbolaki E, Filis D, Athanasakis I, Zoras O, Chalkiadakis G. Ileocolic intussusception precipitated by diagnostic colonoscopy: a case report. Surg Laparosc Endosc Percutan Tech 2012;22:e161-e163. 
11. Lee CK, Shim JJ, Jang JY. Ceco-colic intussusception with subsequent bowel infarction as a rare complication of colonoscopic polypectomy. Endoscopy 2013;45 Suppl 2 UCTN:E106-E107.

12. Min MX, Sklow B, Vaughn BP. Intussusception after routine colonoscopy: a rare complication. ACG Case Rep J 2017;4:e63.

13. Santos-Antunes J, Ramalho R, Lopes S, Macedo G. Colonic intussusception after endoscopic volvulus decompression. Int J Colorectal Dis 2015;30:1425.

14. Marsicovetere P, Ivatury SJ, White B, Holubar SD. Intestinal intussusception: etiology, diagnosis, and treatment. Clin Colon Rectal Surg 2017:30:30-39.
15. Kim YH, Blake MA, Harisinghani MG, et al. Adult intestinal intussusception: CT appearances and identification of a causative lead point. Radiographics 2006;26:733-744.

16. Gayer G, Zissin R, Apter S, Papa M, Hertz M. Pictorial review: adult intussusception--a CT diagnosis. Br J Radiol 2002;75:185-190.

17. Begos DG, Sandor A, Modlin IM. The diagnosis and management of adult intussusception. Am J Surg 1997;173:88-94.

18. Rea JD, Lockhart ME, Yarbrough DE, Leeth RR, Bledsoe SE, Clements RH. Approach to management of intussusception in adults: a new paradigm in the computed tomography era. Am Surg 2007;73:1098-1105. 